\title{
ASSESSMENT OF RELATIONSHIP BETWEEN MEAN RADIUS OF MINERAL FERTILIZER SPREADING AREA AND EXAMINED FEATURES
}

\author{
Artur Przywara ${ }^{1}$, Alexandros Sotirios Anifantis ${ }^{2}$, Simone Pascuzzi ${ }^{2}$, \\ Francesco Santoro ${ }^{2}$, Artur Kraszkiewicz ${ }^{1}$ \\ ${ }^{1}$ University of Life Sciences in Lublin, Poland; ${ }^{2}$ University of Bari Aldo Moro, Italy \\ artur.przywara@up.lublin.pl, alexandrossotirios.anifantis@uniba.it, simone.pascuzzi@uniba.it, \\ francesco.santoro@uniba.it, artur.kraszkiewicz@up.lublin.pl
}

\begin{abstract}
The paper presents results of research in the impact of selected construction parameters of the disc spreader on the mineral fertilizer spreading process. Tests were carried out in a closed room on a constructed measuring stand with the use of three mineral fertilizers (urea, nitrochalk and ammonium sulfate), the selection of which was made due to different physical properties (e.g. bulk density, coefficient of friction, size distribution) and wide application in agriculture. In order to present the impact of factors on the radius of mineral fertilizer spreading area, a four-factor experiment model was adopted, established by the method of complete randomization, in which the independent variables were: type of mineral fertilizer, level of rotational speed of the spreading disc, place of fertilizer application on the disc and angle of vanes on the disc. Results of variance analysis for the fixed model of the mean fertilizer spread radius showed that two independent variables (fertilizer type and disc rotational speed) explain the variance of dependent variable in $78.48 \%$. Results of variance analysis for the linear multiple regression model of the relationship between the mean fertilizer spread radius and studied features showed that $91.27 \%$ of the variability of dependent variable is explained by the model. In the regression equation for the mean fertilizer spreading radius, independent variables include: vane angle $(S)$, rotational speed of the disc $(V)$, specific density of the fertilizer $(G)$ and share of dust fractions $(F P)$.
\end{abstract}

Keywords: centrifugal spreading, mineral fertilizers, fertilization, optimization.

\section{Introduction}

Sustainable agriculture aims at promoting a sustainable farming system, rationally using nature resources, and limiting the negative impact of agriculture on the environment. Many issues related to this problem are associated with, among others, technology of cultivation and processing in plant production [1-7], its quality, storage and use of plant biomass for energy purposes [8-10] or obtaining the energy from renewable sources [11]. High production costs, occupational safety and continuous development in this field require specialization from machine operators, who will be able to meet not only the increase in production quality standards, but also challenges of international regulations [12].

One of the most important factors affecting the size and quality of crops are correctly carried out agrotechnical treatments, among which mineral fertilization occupies a special place. The effectiveness of both mineral and liquid fertilization (digestate [7]) is determined by many factors, among which even distribution of a fertilizer over the surface and shape of the area, are important $[13 ; 14]$. It depends largely on the work quality of the machines used, atmospheric conditions and diligence of the procedure. Proper application of fertilization at the recommended doses taking into account the needs of plants and soil nutrient content allows for achieving high and full-quality crops and does not pose a threat to the environment. On the other hand, excessively high doses, incorrect proportions of nutrients or failure in utilizing a fertilizer by plants can lead to environmental pollution or its degradation [14]. Therefore, in order to avoid undesirable effects on the environment, machines are being studied using mathematical models to simulate and improve the performance of agrotechnical operations [13-18].

\section{Materials and methods}

Field tests were carried out in a closed room on the measuring stand shown in Figure 1. It consisted of $0.5 \mathrm{~m} \times 0.5 \mathrm{~m} \times 0.15 \mathrm{~m}$ trays made in accordance with PN-EN 13739-2 [19], which were arranged in sixteen rows and eleven columns ( $0.5 \mathrm{~m}$ distance between rows and columns). Center of the disc with coordinates $(0 ; 0)$ in the $0 \mathrm{XY}$ system was located at the distance of $0.7 \mathrm{~m}$ from the first edge of the first row of trays.

Three mineral fertilizers (urea, nitrochalk and ammonium sulfate) were used in the research, the choice of which was made due to different physical properties. Relative humidity of air ranged from 52 to $57.7 \%$ and the temperature from 13 to $17^{\circ} \mathrm{C}$. The choice of rotational speed of the disc $(400$ and 
$600 \mathrm{rpm} \cdot \mathrm{min}^{-1}$ ) was made on the basis of literature analysis and dimensional possibilities of the room, in which the tests were conducted. When choosing the place of fertilizer application on the disc, the solutions used in mass-produced spreaders and the need to obtain different distributions of the fertilizer spreading areas were guided. The angle between the OY half-axis from the second quarter of the Cartesian system and the half-line determined by the origin of the coordinate system and passing through vertical projection onto the disc of the appropriate center of the dosing orifice (A and B), was adopted as the parameter for the location of the filling place (Figure 2).

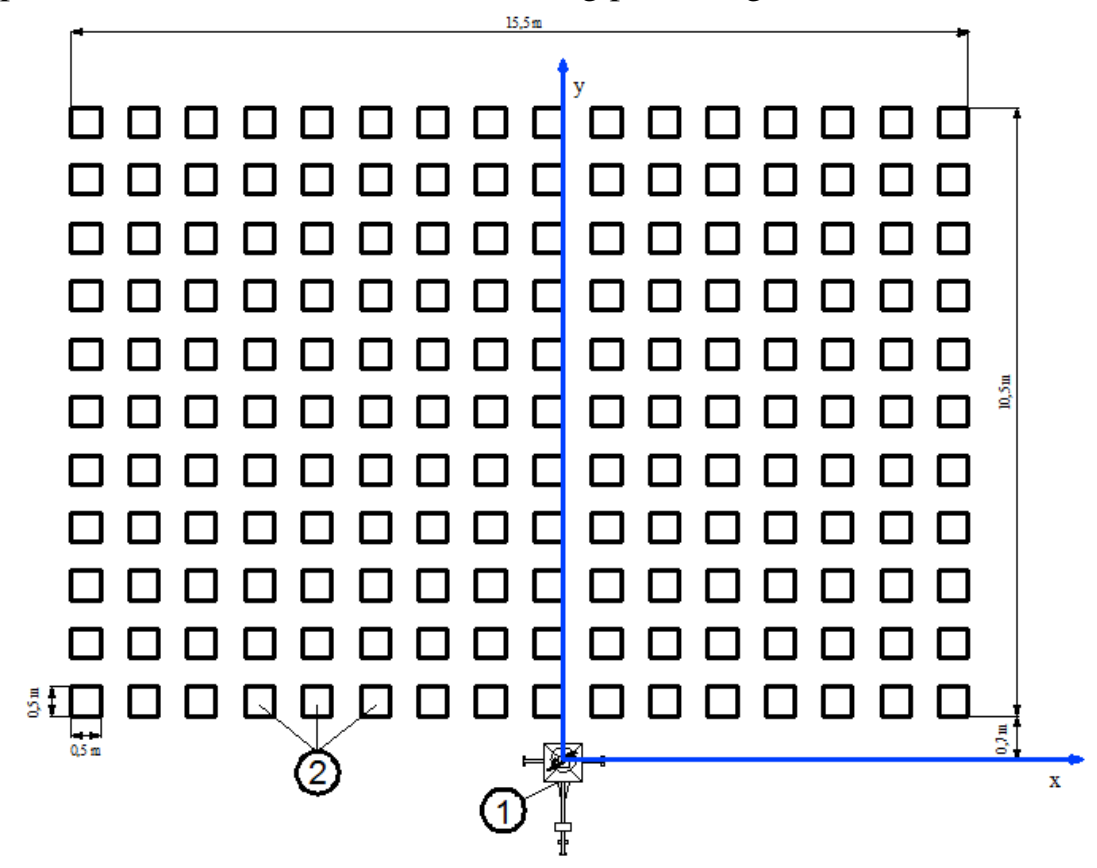

Fig. 1. Scheme of measuring position in the coordinate OXY system:

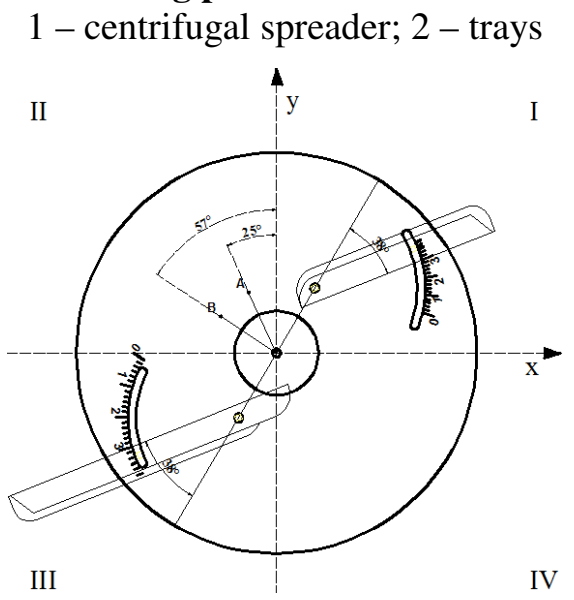

Fig. 2. Location of the orifice centers dosing of fertilizer (A and B) on the surfaces of the disc and the setting of vanes in configuration $\mathrm{L3}$

In order to implement the assumed research program, two positions of vanes on the disc (independent variable necessary for the needs of regression analysis) were adopted (configuration L3 according to the scale on the disc, Figure 2), which allowed for obtaining the fertilizer spreading areas of different shape and dimensions. Vanes $0.32 \mathrm{~m}$ and $0.22 \mathrm{~m}$ long were used for the tests.

The test results obtained from the stand measurements were the basis for determining the parameters of the spatial distribution of the fertilizer distribution area in the polar coordinate system with the center located at the disc rotation point.

The mean radius of the fertilizer spreading area $(R)$ was calculated according to the following relationship [20]: 


$$
\bar{R}=\sum_{i=1}^{n} \sum_{j=1}^{m} f_{i j} r_{i j}
$$

where $f_{i j}$ - share of fertilizer mass in a tray from the $i$-th row and $j$-th column in relation to the sum of the fertilizer mass from all trays (from a given sample), g;

$n$ - number of tray rows;

$m$ - number of tray columns;

$r_{i j}$ - distance from the center of the tray from the $i$-th row and $j$-th column to the beginning of the system (radius length), $\mathrm{m}$.

The results of multivariate analysis of variance for the constant model of the mean radius of the fertilizer spreading area, developed in the SAS 'Local' system, XP_PRO (at the assumed significance level $\alpha=0.05$ ). The coefficient of determination $R^{2}$ was adopted as a measure of explaining the variability of the dependent variable by the constant model. In order to assess the relationship between the examined features, multiple regression analysis was used.

\section{Results and discussion}

The results of the calculated values of mean radius of the spreading area for the three tested fertilizers with significantly different physical properties are presented in Figure 3. The information in Tables 1-3 concerns statistical development of results, which included an analysis of variance for a fixed model of the mean radius of the fertilizer spreading area based on quadruple classification $(\mathrm{N} \times \mathrm{O} \times \mathrm{M} \times \mathrm{L})$ with three observations in each of the sub-classes, as well as variance analysis for the linear multiple regression model of the relationship between the mean fertilizer spread radius and studied features.

Analyzing data referring to the mean spreading radius, it should be stated that the highest values of this parameter were recorded during saltpeter tests (Figure 3). The average value of this radius is up to $7.59 \mathrm{~m}$ for the conditions of the experiment: fertilizer feed point $\mathrm{B}$, rotational speed of the disc $600 \mathrm{rpm}$, position of vanes on the disc L3. The value given is almost three times greater than the mean spreading radius of ammonium sulphate for the following conditions: fertilizer feed point A, disc rotation speed $400 \mathrm{rpm}$, position of vanes on the disc L0.

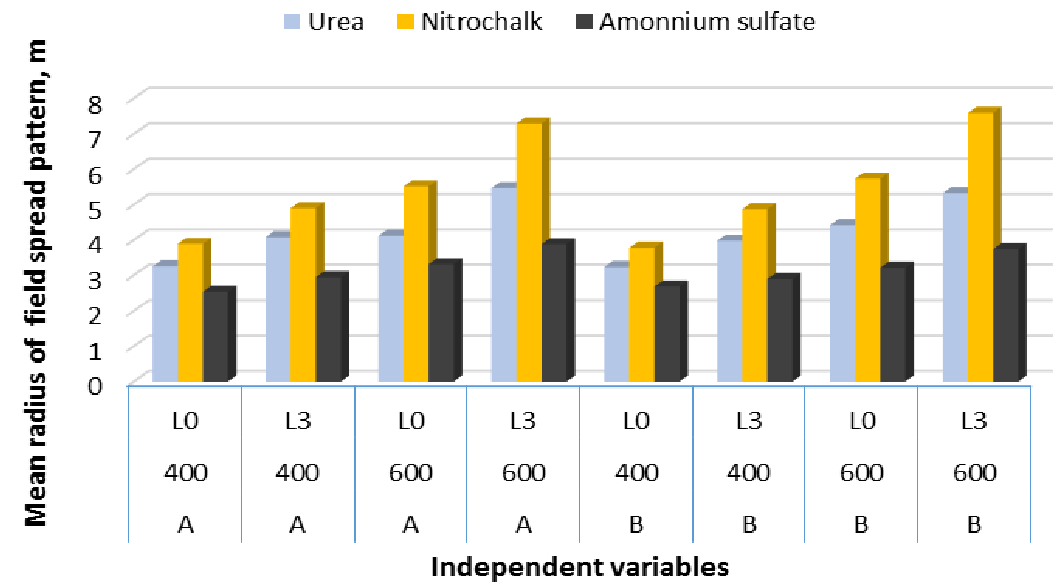

Fig. 3. Mean radius of field spread pattern for urea, nitrochalk and ammonium suflate

Variance analysis for the fixed model of the mean fertilizer spread radius showed that independent variables included account the variance of dependent variable in $99.48 \%$ (Table 1). It should be added, however, that among the main effects, only the fertilizer application point on the disc turned out to be irrelevant for explaining the variability of the mean fertilizer spreading radius. Its share in explaining the variance of dependent variable is only $0.008 \%$. The share of the other main effects (type of fertilizer, rotational speed of the disc, vane position) in explaining the variability of dependent variable is $91.74 \%$. Particularly noteworthy is the fact that only one effect of two-factor interaction (fertilizer $\times$ point of fertilizer feed on disc) turned out to be irrelevant in explaining the variability of mean fertilizer spreading radius. 
Variance analysis for a fixed model of the mean radius of the fertilizer spreading area

\begin{tabular}{|l|c|c|c|c|c|}
\hline Source of variation & $\begin{array}{c}\text { Degrees of } \\
\text { freedom }\end{array}$ & $\begin{array}{c}\text { Sum of } \\
\text { squares }\end{array}$ & $\begin{array}{c}\text { Mean of } \\
\text { squares }\end{array}$ & $\begin{array}{c}\text { Value of the } \\
\boldsymbol{F} \text { function }\end{array}$ & $\begin{array}{c}\text { Probt. }> \\
\boldsymbol{F}\end{array}$ \\
\hline Model & 14 & 123.82 & 8.84 & 783.26 & $<0.0001$ \\
Error & 57 & 0.64 & 0.01 & & \\
Total & 71 & 124.46 & & & \\
\hline R & & & & \\
\hline
\end{tabular}

$R^{2}=99.48 \%$; Average value of mean radius of the fertilizer spreading area $4.28 \mathrm{~m}$;

Standard estimation error 0.106; Coefficient of variation $2.48 \%$

\begin{tabular}{|c|c|c|c|c|c|}
\hline $\mathrm{N}$ & 2 & 63.44 & 31.72 & 2809.03 & $<0.0001$ \\
\hline $\mathrm{O}$ & 1 & 34.24 & 34.24 & 3032.2 & $<0.0001$ \\
\hline $\mathrm{M}$ & 1 & 0.01 & 0.01 & 0.94 & 0.337 \\
\hline $\mathrm{L}$ & 1 & 15.92 & 15.92 & 1409.65 & $<0.0001$ \\
\hline $\mathrm{N} \times \mathrm{O}$ & 2 & 6.16 & 3.08 & 272.55 & $<0.0001$ \\
\hline $\mathrm{N} \times \mathrm{M}$ & 2 & 0.05 & 0.025 & 2.16 & 0.1241 \\
\hline $\mathrm{N} \times \mathrm{L}$ & 2 & 3.02 & 1.51 & 133.76 & $<0.0001$ \\
\hline $\mathrm{O} \times \mathrm{M}$ & 1 & 0.05 & 0.05 & 4.21 & 0.0448 \\
\hline $\mathrm{O} \times \mathrm{L}$ & 1 & 0.89 & 0.89 & 79.54 & $<0.0001$ \\
\hline $\mathrm{M} \times \mathrm{L}$ & 1 & 0.05 & 0.05 & 4.12 & 0.0471 \\
\hline
\end{tabular}

$\mathrm{N}$ - fertilizer, $\mathrm{O}$ - rotational speed of the disc, $\mathrm{M}$ - fertilizer feed point, $\mathrm{L}$ - vane position

Table 2

Assessment of the parameters of the multiple regression model of the relationship between mean fertilizer spread radius and the examined features

\begin{tabular}{|c|c|c|c|c|c|c|c|}
\hline $\begin{array}{c}\text { Source } \\
\text { of } \\
\text { variation }\end{array}$ & $\begin{array}{c}\text { Parameter } \\
\text { evaluation }\end{array}$ & $\begin{array}{c}\text { Standard } \\
\text { error }\end{array}$ & $\begin{array}{c}\text { Relative } \\
\text { standard } \\
\text { error }\end{array}$ & $\begin{array}{c}\text { Sum of } \\
\text { squares }\end{array}$ & $\begin{array}{c}\text { Value of } \\
\text { the test } \\
\text { function }\end{array}$ & Probt. $>\boldsymbol{F}$ & $\begin{array}{c}\text { Partial } \\
\text { correlations }\end{array}$ \\
\hline Constant & 0.81 & 0.48 & 59.26 & 0.47 & 2.84 & 0.097 & - \\
\hline S & -0.035 & 0.0035 & 10.00 & 0.00352 & 98.1 & $<0.0001$ & 0.13 \\
\hline V & 0.0069 & 0.00047 & 6.81 & 0.00047 & 211.01 & $<0.0001$ & 0.32 \\
\hline G & 1.66 & 0.23 & 13.86 & 0.23382 & 50.29 & $<0.0001$ & 0.0042 \\
\hline FP & -0.044 & 0.0022 & 0.50 & 0.0021 & 389.04 & $<0.0001$ & 0.85 \\
\hline
\end{tabular}

Table 3

Variance analysis for the linear multiple regression model of the relationship between mean fertilizer spread radius and the examined features

\begin{tabular}{|l|c|c|c|c|c|}
\hline Source of variation & $\begin{array}{c}\text { Degrees of } \\
\text { freedom }\end{array}$ & $\begin{array}{c}\text { Sum of } \\
\text { squares }\end{array}$ & $\begin{array}{c}\text { Mean of } \\
\text { squares }\end{array}$ & $\begin{array}{c}\text { Value of the } \\
\boldsymbol{F} \text { function }\end{array}$ & Probt. $>\boldsymbol{F}$ \\
\hline Model & 4 & 113.59 & 28.39 & 175.02 & $<0.0001$ \\
\hline Error & 67 & 10.87 & 0.16 & & \\
\hline Total & 71 & 124.46 & & & \\
\hline $\begin{array}{l}R^{2}=91.27 \% \text {; Average value of mean radius of the fertilizer spreading area } 4.28 \mathrm{~m} ; \\
\text { Coefficient of variation } 9.42 \%\end{array}$
\end{tabular}

Based on the calculated values (Tables 2 and 3), the regression equation with the estimation errors can be written in the form:

$$
\begin{gathered}
\bar{R}=0.81-0.035 S+0.0069 V+1.66 G-0.44 F P \pm 0.106 \\
\text { (0.48) (0.0035) (0.00047) (0.23) (0.0022) }
\end{gathered}
$$

The above dependence shows that the predicted (by estimated equation) values of dependent variable, mean fertilizer spread radius $R$, differ from empirical values by $0.106 \mathrm{~m}$ on average. Values given in brackets are average errors of estimation of relevant parameters. They are an estimate of the 
average discrepancy between parameters of the model and its possible assessments. Therefore, it can be said that when estimating the directional coefficient at the level of -0.035 , we make an error of $0.0035 \mathrm{~m}$ on average. Similarly, when estimating the free term at the level of 0.81 , we make an error of $0.48 \mathrm{~m}$ on average. Data in Table 2 show that the average errors of estimation related to values of the corresponding coefficients are very diverse. Estimation error for parameters: vane angle $(S)$, rotational speed of the disc $(V)$, content of dusty fractions in the fertilizer $(F P)$, does not exceed $14 \%$ (from 0.5 to $13.86 \%$ ). On the other hand, for free term, almost $60 \%$ is the assessment error. Table 3 shows that the variable share of dusty fractions in fertilizer has the highest partial correlation coefficient. It amounts to 0.85 . This variable alone explains over $72.25 \%$ (square of the partial correlation coefficient $\times 100 \%$ ) of the variance of dependent variable, after excluding the influence of other independent variables. Slightly over $10 \%$ of variance of dependent variable is explained by variable rotational speed of the disc. However, the share of the other two independent variables (vane angle $S$, and specific density of the fertilizer $G$ ) does not exceed $1.7 \%$ in explaining the variance of dependent variable. Particularly noteworthy is the fact that the variable has a negligible share of specific density of the fertilizer in explaining the variability of dependent variable: it is only $0.0018 \%$. It should be added, however, that the variable regression coefficient of the share of dusty fractions has a minus sign, which means that the increase in the independent variable corresponds to smaller value of the dependent variable (mean fertilizer spread radius $R$ ). Based on this relationship, it can be concluded that increasing the share of dusty fractions in mineral fertilizers reduces the working width. This is confirmed, among others, by the information contained in the spreading tables, without which the fertilizing process carried out with disc spreaders cannot be carried out properly.

\section{Conclusions}

1. Results of the variance analysis for the fixed model of the mean fertilizer spread radius showed that two independent variables (fertilizer type and disc rotational speed) explain the variance of dependent variable in $78.48 \%$. Another effect that makes a significant contribution to explaining the variability of the dependent variable is the position of vanes on the spreading disc. This share amounts to $12.79 \%$. The share of all double interaction effects in explaining variances of the mean fertilizer spread radius does not exceed $8.21 \%$. However, the fertilizer feed point on the disc turned out to be a parameter that did not affect the mean radius of the spreading area.

2. Results of the variance analysis for the linear multiple regression model of the relationship between the mean fertilizer spread radius and the studied features showed that $91.27 \%$ of the variability of dependent variable is explained by the model. In the regression equation for the mean fertilizer spreading radius, independent variables include: vane angle $(S)$, rotational speed of the disc $(V)$, specific density of the fertilizer $(G)$ and the share of dust fractions $(F P)$. Directional coefficient of variable fertilizer feed point on the disc $(P)$ proved to be insignificant at the required level of significance. The average errors of estimation related to the values of the corresponding coefficients are very diverse. Estimation error for parameters: vane angle $(S)$, rotational speed of the disc $(V)$, content of dusty fractions in the fertilizer $(F P)$ does not exceed $14 \%$ (from 0.5 to $13.86 \%$ ). On the other hand, for free term, almost $60 \%$ is an assessment error. Variable share of dusty fractions $(F P)$ alone explains over $72.25 \%$ of the variance of dependent variable. The variable regression coefficient of dusty fractions share has a minus sign, which means that the increase in the independent variable corresponds to a smaller value of the dependent variable.

\section{References}

[1] Sobczak P., Mazur J., Zawiślak K., Panasiewicz M., Żukiewicz-Sobczak W., Królczyk J., Lechowski J. Evaluation of Dust Concentration During Grinding Grain in Sustainable Agriculture. Sustainability, 2019, vol. 11(17), 4572, DOI: 10.3390/su11174572.

[2] Żukiewicz-Sobczak W., Sobczak P., Rogóż A., Wojtyła-Buciora P., Kozak M., Zagórski J. Valuation of the content of selected elements in herbs cultivated in organic farms in the Lublin region. Proceedings Paper, Farm Machinery And Processes Management In Sustainable Agriculture, 2017, pp. 461-464, DOI: 10.24326/fmpmsa.2017.83. 
[3] Kachel-Jakubowska M., Matwijczuk A., Mariusz Gagoś. Analysis of the physicochemical properties of post-manufacturing waste derived from production of methyl esters from rapeseed oil. Int. Agrophys. 2017, 31(2): pp. 175-182 DOI: https://doi.org/10.1515/intag-2016-0042.

[4] Kachel M., Matwijczuk A., Sujak A., Czernel G., Niemczynowicz A., Nowicka A. The Influence of Copper and Silver Nanocolloids on the Quality of Pressed Spring Rapeseed Oil. Agronomy 2019, 9(10), $643 \mathrm{p}$.

[5] Blicharz-Kania, A., Pecyna, A., Krajewska, M., Andrejko, D., Szmigielski, M., Zawiślak, K., Sobczak, P., Berbec, A. Chemical properties of tobacco seed oil. Przemysł Chemiczny, 2018, vol. 97(11), pp. 1906-1909, DOI: 10.15199/62.2018.11.18

[6] Kozak-Kalita M., Sobczak P., Zawiślak K., Mazur J., Panasiewicz M., Żukiewicz-Sobczak W. Influence of uv-c radiation on the microbiological purity in selected species of herbs. Health Problems of Civilization, 2018.

[7] Przywara A., Kachel M., Koszel M., Leszczyński N., Kraszkiewicz A., Anifantis A. S. The influence of digestate on the static strength of spring rapeseeds (Brassica napus var. arvensis). Sustainability, vol. 11(7), 2133, 2019. DOI: 10.3390/su11072133.

[8] Russo G., Verdiani G., Anifantis A.S. Re-use of agricultural biomass for nurseries using proximity composting. Contemporary Engineering Sciences, vol. 9(24), 2016, pp. 1151-1182.

[9] Kraszkieicz A., Kachel M., Parfiniuk S., Zając G., Niedziółka I., Sprawka M. Assessment of the possibility of using hemp biomass (Cannabis sativa L.) for energy purposes: a case study. Appl. Sci.-Basel 2019 Vol. 9(20) 4437, DOI: 10.3390/app9204437.

[10] Kraszkiewicz A., Stryjecka M., Nowosad N., Kocira S. Obciążenie środowiska produktami spalania peletów z biomasy roślinnej w kotle górnego spalania (Loading the environment with products of burning biomass pellets in the bottom-up combustion boiler). Rocz. Ochr. Śr. 2018 T. 20 pp.1269-1285. (In Polish).

[11] Anifantis A.S., Pascuzzi S., Scarascia Mugnozza G. Geothermal source heat pump performance for a greenhouse heating system: An experimental study. Journal of Agricultural Engineering, vol. 47(3), 2016, pp.164-170.

[12] Santoro F., Anifants A.S., Ruggiero G., Zavadskiy V., Pascuzzi S. Lightning Protection Systems Suitable for Stables: A Case Study. Agriculture Volume 9(4), 2019, 72 - DOI: 10.3390/agriculture9040072.

[13] Przywara A. The impact of structural and operational parameters of the centrifugal disc spreader on the spatial distribution of fertilizer. Agriculture and Agricultural Science Procedia, vol. 7, 2015, pp. 215-222. DOI: 10.1016/j.aaspro.2015.12.021.

[14]Dintwa E., Tijskens E., Olieslagers R., De Baerdemaeker J., Ramon H. Calibration of a spinning disc spreader simulation model for accurate site-specific fertiliser Application. Biosystems Engineering, 88 (1), 2004, pp. 49-62.

[15] Anifantis A.S., Camposeo S., Vivaldi G.A., Santoro F., Pascuzzi S. Comparison of UAV photogrammetry and 3D modeling techniques with other currently used methods for estimation of the tree row volume of a super-high-density olive orchard. Agriculture (Switzerland), vol. 9(11), 2019, 233.

[16] Bulgakov V., Pascuzzi S., Santoro F., Anifantis A.S. Mathematical Model of the Plane-Parallel Movement of the Self-Propelled Root-Harvesting Machine. Sustainability Volume 10(10), 2018, 378 - DOI: 10.3390/su10103614.

[17] Bulgakov V., Pascuzzi S., Nadykto V., Ivanovs S. A mathematical model of the plane-parallel movement of an asymmetric machine-and-tractor aggregate. Agriculture (Switzerland), vol.8(10), 2018, 151.

[18] Abbou-ou-Cherif E.M., Piron E., Chateauneuf A., Vilette S.,On-the-field simulation of fertilizer spreading: Part 3 - Control of disk inclination for uniform application on undulating fields. Computers and Electronics in Agriculture 158(158), 2019, pp. 150-158.

[19]PN-EN 13739-2 Polska Norma. 2004. Maszyny rolnicze. Rozsiewacze i siewniki rzutowe nawozów stałych. Ochrona środowiska. Metody badań (Agricultural machinery. Solid fertilizer spreaders and seed drills. Environmental Protection. Test methods). (In Polish).

[20] Koko J., Virin T. Optimization of a fertilizer spreading process. Mathematic and Computers in Simulation, 79(10), 2009, pp. 3099-3109. 